Pub. 552

\title{
Trichophyton verrucosum em bovinos com pele hígida e com lesões*
}

\author{
Trichophyton verrucosum in bovine with skin healthy and with lesions \\ Erica Silva da Silveira ${ }^{1}$, Márcia de Oliveira Nobre ${ }^{2}$, Lorena Leonardo de Souza ${ }^{1}$, \\ Renata Osório de Faria ${ }^{1}$, Marlete Brum Cleff ${ }^{1} \&$ Mário Carlos Araújo Meireles ${ }^{3}$
}

\begin{abstract}
RESUMO
Dermatofitose é uma micose cutânea determinada por um grupo de fungos chamados dermatófitos que infectam estruturas queratinizadas do homem e animais, causada por espécies do gênero Trichophyton, Microsporum e Epidermophyton. O Trichophyton verrucosum, dermatófito de origem zoofílica, é importante na dermatofitose bovina. O presente trabalho foi desenvolvido com o objetivo de verificar a presença de T. verrucosum na pele hígida de bovinos e estudar casos clínicos de dermatofitose relacionando-os com a sazonalidade, idade e sexo. Foram estudados 313 bovinos, sendo 171 com pele hígida e 142 com lesões compatíveis com dermatofitose. As amostras foram colhidas pela técnica do tapete e por raspado de pele e pêlos, cultivadas em ágar Sabouraud com cloranfenicol e cicloheximida, enriquecido com tiamina e inositol e incubados à $37^{\circ} \mathrm{C}$ por um período de até 30 dias. O isolamento do T. verrucosum ocorreu em somente duas $(1,2 \%)$ amostras de pele hígida e em $136(95,8 \%)$ amostras de bovinos com lesões, principalmente naquelas procedentes de animais com menos de um ano de idade (92,8\%), machos (58,7\%), e no período de outono e inverno (97,9\%). Os resultados demonstram que o T. verrucosum em pele hígida de bovinos é um fungo de transição, ocasional e não-residente, e o desenvolvimento de dermatofitose ocorre preferencialmente durante o outono e inverno, sendo os jovens e machos os mais afetados.
\end{abstract}

Descritores: Trichophyton verrucosum, bovino, dermatófitos, dermatofitose.

\begin{abstract}
Dermatophytosis is a cutaneous mycosis caused by a group of fungus called dermatophytes that infect the keratin structures of the man and animals. This mycosis is caused by species of the gender Trichophyton, Microsporum and Epidermophyton. Trichophyton verrucosum, dermatophyte of zoophilic origin, is important in the bovine dermatophytosis. This study aimed to investigate the presence of T. verrucosum in healthy skin of bovines and to study clinical cases of dermatophytosis, as well as to relate their association with season of the year, age and sex. A total of 313 bovine, of which 171 showing healthy skin and remaining 142 with skin lesions similar to dermatophytosis, was studied. The samples were collected using the carpet technique and scraped of skin and hair cultivated in agar Sabouraud with cloramphenicol and cicloheximide, enriched with thiamin and inositol and incubated at $37^{\circ} \mathrm{C}$ for up to 30 days. T. verrucosum was isolated in only two (1.2\%) samples of bovine with healthy skin and in 136 (95.8\%) samples of animals with lesions. Animals with less than one year of age (92.8\%), males (58.7\%), and in the autumn and winter period (97.8\%) showed higher frequency of $T$. verrucosum. The results indicate that $T$. verrucosum in healthy skin of bovine is a transition fungus, occasional and no resident. In addition, dermatophytosis occurs mainly during the autumn and winter, being young and males the most affected.
\end{abstract}

Key words: Trichophyton verrucosum, bovine, dermatophytes, dermatophytosis.

* Trabalho originado da Dissertação de Mestrado do primeiro autor. ${ }^{1}$ Programa de Pós-Graduação em Veterinária. Faculdade de Veterinária de Pelotas, Universidade Federal de Pelotas (UFPel). ${ }^{2}$ Programa de Pós-Graduação em Ciências Veterinárias - FAVET/UFRGS. ${ }^{3}$ Departamento de Medicina Veterinária Preventiva - Faculdade de Veterinária - UFPel. CORRESPONDÊNCIA: M.C.A. Meireles [e-mail: meireles@tche.com.br] Faculdade de Veterinária, UFPel. Campus Universitário; 96010-900 Pelotas, RS - Brasil. 
Dermatofitose é uma micose cutânea determinada por fungos dermatófitos que infectam estruturas queratinizadas do homem e animais, causadas por espécies dos gêneros Trichophyton, Microsporum e Epidermophyton [16]. O Trichophyton verrucosum é um dermatófito de origem zoofílica adaptado em bovinos e fatores como aglomerações, umidade, calor, estresse e imunodeficiência do animal, predispõem para a passagem da forma sapróbia para a patogênica, desenvolvendo lesões de dermatofitose as quais são caracterizadas por alopecia, presença de crostas e prurido $[4,16]$.

O meio de cultivo para T. verrucosum deve ser necessariamente enriquecido com tiamina e inositol. Os cultivos de $T$. verrucosum crescem lentamente, sendo incubados preferencialmente a temperatura de $37^{\circ} \mathrm{C}$ durante 30 dias $[6,16]$.

No Rio Grande do Sul, a dermatofitose bovina por T. verrucosum foi primeiramente relatada em 1928 [10] em animais importados, sendo que a partir de 1966 foram documentados novos casos, isolados ou epizooóticos, com transmissão para humanos [7-9].

Considerando o clima propício e a importância econômica, na região sul do Rio Grande do Sul, da produção de bovinos, foi desenvolvido este trabalho com o objetivo de pesquisar a presença de T. verrucosum em pele hígida e com lesões de bovino, relacionando o isolamento do dermatófito com sazonalidade, sexo e idade dos animais.

\section{MATERIAIS E MÉTODOS}

O estudo foi desenvolvido durante dois anos em 15 propriedades rurais de criação de bovinos de corte e/ou leite, localizadas em dez municípios da região sul do Rio Grande do Sul (Pelotas, Capão do Leão, Morro Redondo, Pedras Altas, Camaquã, Rio Grande, Piratini, Arroio Grande, Herval e Bagé). Foram colhidas 313 amostras de pele e pêlos (Tabela 1), das quais 171 procediam de bovinos com pele hígida $(\mathrm{BH})$ e 142 de bovinos com lesões (BL), as quais foram caracterizadas por alopecia circular, eritema e crostas, localizadas principalmente na cabeça e pescoço (Figura 1b). Para estudar a sazonalidade do T. verrucosum as colheitas das amostras foram classificadas de acordo com as estações do ano que foram agrupadas em primavera/verão e outono/inverno (Tabela 1).
As amostras de ambos os grupos, $\mathrm{BH}$ e $\mathrm{BL}$ foram colhidas após desinfecção prévia do local da coleta com álcool $70^{\circ}$. No primeiro grupo (BH), foi utilizada a técnica do tapete [11], obtendo-se o material através de fricção de tapete estéril de $5 \times 5 \mathrm{~cm}$, na região da tábua do pescoço, sendo cultivados em placas Petri contendo ágar Sabouraud dextrose com cloranfenicol e ciclohexamida ${ }^{1}$, acrescido de $10 \%$ de Inositol $^{2}$ e $10 \%$ de Tiamina ${ }^{3}$. As amostras do segundo grupo (BL) foram colhidas através de raspado de pele com bisturi estéril das bordas das lesões, sendo realizado exame direto, com solução de hidróxido de potássio a $20 \%$, entre lâmina e lamínula e posteriormente observado ao microscópio ótico (400x) e foram também cultivadas em tubos de ensaio contendo o mesmo meio descrito anteriormente. Todos os cultivos foram mantidos em estufa bacteriológica em temperatura de

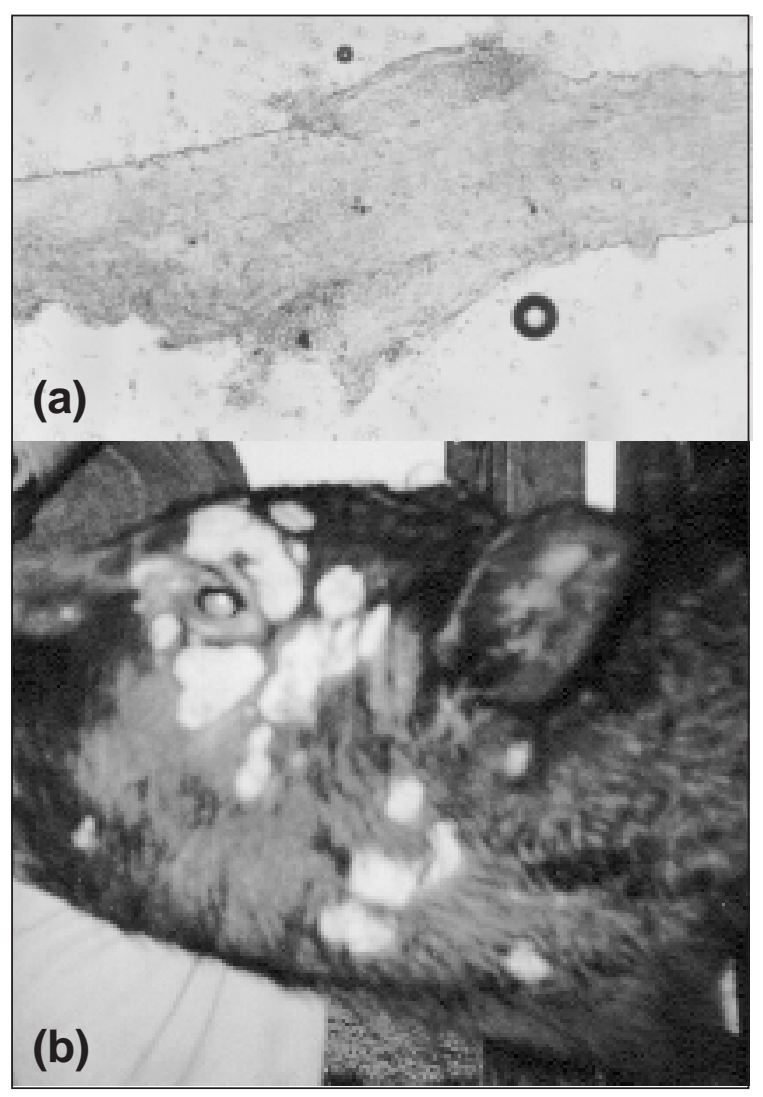

Figura 1. Exame direto com hidróxido de potássio a $20 \%$ demonstrando grande quantidade de artroconídios ao redor do pêlo (X400) (a). Lesões circulares, com alopecia, crostas e eritema em bovino com dermatofitose por Trichophyton verrucosum (b). 
Tabela 1. Procedência das amostras e o isolamento do Trichophyton verrucosum nos grupos de bovinos hígidos e com lesões segundo sexo, idade e época de colheita do material, no período de 1998 a 2000, em municípios da região sul do Rio Grande do Sul.

\begin{tabular}{|c|c|c|c|c|c|}
\hline \multirow{2}{*}{\multicolumn{2}{|c|}{ Parâmetros }} & \multicolumn{3}{|c|}{ Amostras } & \multirow{2}{*}{$\begin{array}{c}\text { T. verrucosum } \\
\mathrm{n}-(\%)\end{array}$} \\
\hline & & $\mathrm{BH} \mathrm{n}^{\circ}$ & BL nำ & Total $\mathrm{n}^{\circ}$ & \\
\hline \multirow{2}{*}{ Sexo } & Machos & 56 & 86 & 142 & $81(58,7)^{*}$ \\
\hline & Fêmeas & 115 & 56 & 171 & $57(41,3)$ \\
\hline \multirow{4}{*}{ Idade } & $<1$ ano & 33 & 127 & 160 & $128(92,8)^{*}$ \\
\hline & 1-2 anos & 26 & 06 & 32 & $9(6,5)$ \\
\hline & 3-4 anos & 76 & 09 & 85 & $1(0,7)$ \\
\hline & $>5$ anos & 36 & - & 36 & - \\
\hline \multirow{2}{*}{ Estação } & Primavera/Verão & 58 & 3 & 61 & $3(2,2)$ \\
\hline & Outono/Inverno & 113 & 139 & 252 & $135(97,8)^{*}$ \\
\hline \multicolumn{2}{|c|}{ Total geral } & 171 & 142 & 313 & $138(100)$ \\
\hline
\end{tabular}

BH - Bovinos hígidos; BL - Bovinos com lesões; $n$ - número absoluto; \% - porcentual; * $p<0,01$.

$37^{\circ} \mathrm{C}$ e incubados por um período de até 30 dias, quando foram submetidos a estudo macro e micromorfológico.

A análise dos resultados foi realizada utilizando o programa Statistix (version 1.0 - 1996), a partir das fichas de campo e dos resultados obtidos no laboratório, os dados foram codificados e digitados, obtendo-se as frequiências simples das variáveis que posteriormente foram cruzadas em tabelas dois por dois, utilizando-se o teste de Qui-quadrado.

\section{RESULTADOS}

Das 171 amostras de animais com pele hígida, somente duas amostras $(1,2 \%)$ foram positivas para T. verrucosum, e das amostras de bovinos com lesões (142), $136(95,8 \%)$ apresentaram exame direto positivo (Figura 1a) e isolamento de T. verrucosum, nas quais houve crescimento de colônias de cor branca ou ocre, cerebriforme ou pregueada, cérea e glabrosa e no exame micromorfológico foi observada a presença de grande quantidade de clamidosporos em cadeia. Todas as amostras que foram positivas no exame direto também apresentaram isolamento de T. verrucosum, demonstrando assim, existir uma relação estatística altamente significante $(\mathrm{p}<0,001)$ entre a presença de lesões de dermatofitose em bovinos e o isolamento deste dermatófito.

Das amostras que apresentaram isolamento de T. verrucosum (Tabela 1), 128 (92,8\%) procediam de animais com menos de um ano de idade, nove $(6,5 \%)$ entre um a dois anos e uma $(0,7 \%)$ com cinco ou mais anos, demonstrando haver uma relação estatisticamente significativa $(p<0,01)$ entre $o$ isolamento deste dermatófito e animais com menos de um ano de idade.

$\mathrm{O}$ isolamento do T. verrucosum foi mais freqüente em machos do que em fêmeas, com respectivamente $81(58,7 \%)$ e $57(41,3 \%)$ amostras positivas, tendo sido demonstrada uma relação estatisticamente significativa $(\mathrm{p}<0,01)$.

Em relação à estação do ano, a maior frequiência de isolamento de $T$. verrucosum ocorreu no período do outono/inverno com $135(97,8 \%)$ amostras positivas enquanto somente três $(2,2 \%)$ foram positivas no período de primavera/verão, demonstrando haver uma diferença estatisticamente significativa $(p<0,01)$ entre as estações do ano, para o isolamento do T. verrucosum (Tabela 1).

\section{DISCUSSÃO}

No grupo de animais hígidos (BH), a frequiência de $T$. verrucosum foi de $1,2 \%$, demonstrando que embora este dermatófito seja zoofílico, com o habitat na pele de bovinos hígidos [4,17], as frequiências obtidas são baixas, entre 0-17\% [13,17,18]. Alta positividade desse dermatófito foi demonstrada em um lote de animais sadios, provenientes de um rebanho que apresentavam sinais clínicos de dermatofitose, em que $40 \%$ dos bovinos foram positivos para T. verrucosum [15]. 
O T. verrucosum foi o único dermatófito isolado nos animais estudados, e este agente tem sido o mais freqüentemente isolado de dermatofitoses bovinas $[2,4]$. Freqüência encontrada do T. verucosum $(95,8 \%)$ nos bovinos com lesões (BL) foi similar à obtida em estudo no Rio Grande do Sul [12], no entanto, há registro de freqüência menor (33\%) no mesmo estado [3]. Nos bovinos com lesões de dermatofitose em que o T. verrucosum não foi isolado $(4,2 \%)$ é necessário considerar a possibilidade dos animais estarem em processo de cura espontânea [2], não havendo persistência do dermatófito em estado latente na pele ou no pêlo do bovino [5].

A maior freqüência de isolamento de T. verrucosum $(97,8 \%)$ ocorreu durante o outono e o inverno justificado pelo aumento da disseminação do $T$. verrucosum em baixas temperaturas, devido à aglomeração dos animais, à alta umidade relativa do ar e à menor incidência solar [17], bem como a pelagem dos bovinos, que em períodos de clima frio apresentam pêlos mais longos, criando um microclima favorável à proliferação fúngica [18].

Quanto à idade, verificou-se que 128 amostras $(92,8 \%)$ positivas para $T$. verrucosum eram provenientes de animais com menos de um ano de idade. A susceptibilidade de animais jovens ao T. verrucosum esta relacionada com a ausência do desenvolvimento de imunidade prévia para o dermatófito $[2,17]$. Ressalta-se ainda que $89,4 \%$ das amostras do grupo BL procediam de animais com menos de um ano de idade, fato este que demonstra a alta casuística de dermatofitose nesta faixa etária.
Os bovinos machos foram mais acometidos pelo T. verrucosum do que as fêmeas, visto que o número total de amostras colhidas de machos (142) foi menor do que o de fêmeas (171), sendo que nas 138 amostras em que foi obtido o isolamento do agente, $58,7 \%$ procediam de machos e 41,3\% de fêmeas. Aspectos comportamentais distintos entre os sexos como as disputas comuns entre machos, que facilita a transmissão do dermatófito de animais doentes para sadios [19], podem ter determinado uma maior frequiência de T. verrucosum em machos [14]. Entretanto, já foi demonstrado in vitro a inibição do crescimento de dermatófitos na presença de hormônios femininos, sugerindo a possibilidade de ocorrer um mecanismo de regulação da patogênese da dermatofitose em fêmeas [1], o que poderia justificar uma menor frequiência de T. verrucosum nas fêmeas estudadas.

\section{CONCLUSÃO}

O Trichophyton verrucosum na pele de bovinos hígidos é um fungo de transição, ocasional e não-residente. Nos bovinos com dermatofitose o $T$. verrucosum acometeu principalmente jovens e machos, sendo o outono e o inverno os períodos sazonais que melhor propiciam condições para o desenvolvimento desta micose em bovinos.

\section{NOTAS INFORMATIVAS}

\footnotetext{
${ }^{1}$ Bacto Mycobiotic Agar desidratado - Difco Laboratories Detroit, Michigan, USA.

${ }^{2}$ Inositol - Vetec Química Fina, Rua do Rocha, 168, Rocha, RJ, Brasil.

${ }^{3}$ Thiamine - Sigma Chemical CO. PO. Box 14508, St. Louis, MO, USA.
}

\section{REFERÊNCIAS}

1 Clemons K.V., Schär G., Stover E.P., Feldman D. \& Stevens D.A. 1988. Dermatophyte-hormone relationships: characterization of progesterone-binding specificity and growth inhibition in the genera Trichophyton and Microsporum. Journal of Clinical Microbiology. 26: 2110-2115.

2 Elad D. \& Segal E. 1995. Immunogenicity in calves of a crude ribosomal fraction of Trichophyton verrucosum: a field trial. Vaccine. 13: 83-87.

3 Ferreiro L., Rocha D.E.L.C. \& Soares C.H. 1982/83. Etiologia das dermatomicoses de animais domésticos, com especial ênfase nas dermatofitoses. Arquivos da Faculdade de Veterinária UFRGS. 10-11: 88-92.

4 Franc M. \& Cadiergues M.C. 1992. Les teignes bovines. Revue de Médecine Vétérinarie. 143: 91-94.

5 Kielstein P. 1990. Systematic control of dermatophytosis profounda of cattle in the former GDR. Mycoses. 33: 575-579.

6 Lacaz C.S., Porto E., Heins-Vaccari E.M. \& Melo, N.T. 1998. Identificação dos fungos In: Fungos, actinomicetos e algas de interesse médico. São Paulo: Sarvier/FAPESP. pp. 55-85.

7 Londero A.T. \& Fischman O. 1966. Trichophyton verrucosum in Brazil. Mycopathologia. 28: 353-358. 
8 Londero A.T. \& Fischman O. 1969. Epidemia de tinha por Trichophyton verrucosum. Revista Brasileira de Pesquisa Médica e Biológica. 2: 241-244.

9 Londero A.T., Ramos C.D. \& Lopes J.O., 1969. Tinha por Trichophyton verrucosum em bovinos no Rio Grande do Sul. Revista Brasileira de Pesquisa Médica e Biológica. 2: 37-40.

10 Magalhães O. 1928. Ensaios de Micologia. Memórias do Instituto Oswaldo Cruz. 21: 173-179.

11 Mariat F. \& Adam-Campos C. 1967. La technique du carré de tapis, méthode simple de prélèvement dans les mycoses superficielles. Annales de l'Institut Pasteur. 113: 666-669.

12 Meireles M.C.A., Riet-Correa F., Brasil Filho J.A.B., Schild A.L., Anciuti M.A. \& Ribeiro G.A. 1986. Ocorrência de dermatofitose em bovinos na região sul do Rio Grande do Sul. In: Anais do XX Congresso Brasileiro de Medicina Veterinária (Cuiabá, Brasil). p.264.

13 Moretti A., Boncio L., Pasquali, P. \& Fioretti D.P. 1998. Epidemiological aspects of dermatophyte infections in horses and cattle. Zentralblatt für Veterinarmedizin. 45: 205-208.

14 Nooruddin M. 1994. Clinical findings and severity of dermatophytosis in buffaloes, cattle and their attendants. Buffalo Bulletin. 13: 56-60.

15 Ollhoff R.D. 1997. O uso da escova de unha como método de obtenção de material para o diagnóstico micológico da tricofitose bovina. In: Anais do XIV Congresso Brasileiro de Medicina Veterinária (Gramado, Brasil). p. 308.

16 Rippon J.W. 1988. Dermatophytosis and dermatomycosis. In: Medical Mycology. Philadelphia: W.B. Saunders, pp. 169275.

17 Singh A.P., Yadav, T.L.J.S., Singh A.P. \& Sharma, S.N. 1997. Clinico-epidemiological studies on bovine dermathophytosis in and around Bikaner. Indian Journal of Animal Sciences. 68: 845-848.

18 Siqueira P.A., Peres R.M., Coutinho-Filho V.J.L., Gompertz O.F., Russumano, O.M.R., Meireles M.C. \& Campos B.E.S. 1990. Estudo da flora fúngica do tegumento externo de bovinos e parte aérea de plantas forrageiras em São José do Rio Preto. Boletim da Indústria Animal. 47: 1-10.

19 Takatori K., Takahashi A., Kawai S., Ichijo S. \& Hasegawa A. 1993. Isolation of Trichophyton verrucosum from lesional and non-lesional skin in calves. Journal of Veterinary Medical Science. 55: 343-344. 